\title{
RISK FACTORS OF HETEROTOPIC OSSIFICATION IN TRAUMATIC SPINAL CORD INJURY
}

\author{
Cláudia Virgínia C. Coelho', Paulo Sergio S. Beraldo²
}

\begin{abstract}
Objective: Heterotopic ossification ( $\mathrm{HO})$ is a complication of the spinal cord injury (SCl). It can result in anchylosis, harming the rehabilitation and quality of life. Previous publications had not elucidated the relation between possible independent variables, the aim of this study. Method: From 230 patients with SCl, admitted in 1998 at Hospital SARAH Brasilia, 33 with $\mathrm{HO}$ (14.3\%; Cl95\% 10.1-19.6) were compared with 33 controls. The risk factors had been tested in bivariate analysis and in a model of logistic regression. Results: Spasticity (odds ratio=3.8; Cl95\% 1.15-12.30), number of pressure ulcers (2.1; Cl95\% 1.08-3.89) and time lapsed since the injury (1.1; C195\% 1.02-1.24) were independently associated with $\mathrm{HO}$. There was a confounder effect among these variables, without interaction. Conclusion: Spasticity, pressure ulcer and time of injury are associated with $\mathrm{HO}$ in spinal cord injury. The first two factors can be prevented and treatable.
\end{abstract}

KEY WORDS: heterotopic ossification, spinal cord injuries, pressure ulcer, muscle spasticity, risk factors, multivariate analysis.

\section{Fatores de risco da ossificação heterotópica na lesão medular traumática}

Resumo - Objetivo: A ossificação heterotópica (OH) é uma complicação da lesão medular traumática (LMT). Pode resultar em anquilose, prejudicando a reabilitação e a qualidade de vida. Estudos prévios não elucidaram a relação entre as potenciais variáveis independentes, propósito desse estudo. Método: De 230 pacientes com LMT, admitidos em 1998 no Hospital SARAH Brasilia, 33 tiveram o diagnóstico de OH (14,4\%; IC95\% 10,1-19,6), que foram comparados a 33 controles. Os fatores de risco foram testados de forma bivariada e num modelo de regressão logística. Resultados: Espasticidade (razão de chances 3,8; IC95\% 1,15-12,30), número de escaras $(2,1 ; 1,08-3,89)$ e tempo de lesão $(1,1 ; 1,02-1,24)$ encontraram-se associadas, de forma independente, à presença de $\mathrm{OH}$. Havia um efeito confundidor entre essas variáveis, porém sem interação. Conclusão: Espasticidade, escaras e tempo de lesão estão associados à $\mathrm{OH}$ na lesão medular traumática. Os dois primeiros são passiveis de prevenção e tratamento.

PALAVRAS-CHAVE: ossificação heterotópica, traumatismos da medula espinal, úlcera de pressão, espasticidade muscular, fatores de risco, análise multivariada.

Heterotopic ossification is a common complication of traumatic spinal cord injuries with a prevalence ranging from 5 to $50 \%$, depending upon the studies design and the diagnosis method ${ }^{1-4}$. The progression of heterotopic ossification may lead to decreases in the range of motion and anchylosis and has a negative impact on the rehabilitation processes ${ }^{3}$. The most affected joints are the hips $(60 \%-70 \%)$ and knees $(20 \%-30 \%)$.

The etiology and pathogenesis of heterotopic ossification are still unknown, but some factors appear to favor its onset in patients with traumatic spinal cord inju- ries: gender, age, completeness of the injury, presence of spasticity and decubitus ulcers ${ }^{5-8}$. However, various confounding and interactive factors may be present. Despite the importance of heterotopic ossification, no studies were found which employed multivariate analyses to determine independent risk factors.

Therefore, the purpose of the present study was to determine, using a case-control design, the independent risk factors associated with the development of heterotopic ossification based upon a hospital sample of patients with spinal cord injuries.

${ }^{1}$ Médica Radiologista, Mestre em Ciências da Reabilitação, Hospital SARAH Centro, Brasília DF, Brazil; ${ }^{2}$ Médico, Doutor em Clínica Médica, Centro SARAH de Formação e Pesquisa, Programa de Pós-Graduação em Ciências da Reabilitação, Hospital SARAH Centro, Brasília DF, Brazil. 


\section{METHOD}

A total of 331 adult patients with traumatic spinal cord injuries were admitted to the Sarah Brasilia Hospital during the year of 1998. From this sample, patients younger than 15 years of age and with time since injury over two years were excluded. Thus, out of the $230(70 \%)$ selected patients, 33 (14.4\%, confidence intervals, C195\% 10.1 to 19.6) had periarticular heterotopic ossification in the hip and/or knee joints, as confirmed by X-rays. During the same period, 33 other patients were also investigated by images to exclude heterotopic ossification and this group served as controls, configuring a case-control design with a 1:1 ratio. All individuals' data included in the analysis were collected retrospectively based on medical records of patients hospitalized at Hospital SARAH Brasilia, Spinal Cord Injury Program. The hospital's ethics committee approved the study.

The following variables were investigated: gender, age, and time since injury, both at hospital admission; length of stay; type of accident; other associated traumatic injuries; motor level and completeness of the injury ${ }^{9}$; reports of previous rehabilitation; degrees of spasticity; urinary tract complications; number of pressure ulcers; presence of deep venous thrombosis; and current or previous histories of smoking.

For characterization purposes, a classification of the severity of heterotopic ossification was developed as follows: mild (tenuous neo-bone formation in soft tissues adjacent to the joints), moderate (ossification in tissues adjacent to various anatomical bone prominences with well defined contours and without articular anchylosis), and severe (wide extensions of the heterotopic ossification and the presence of anchylosis).

Spasticity of the limbs was assessed by the Ashworth scale ${ }^{10}$, which quantifies the resistance of the movement during passive extension movements. These scores range from zero (flaccid, $F$ or zero) to 4 (the affected joint is rigid in flexion or extension). In the analyses, the degrees of spasticity were reclassified combining the scores: absent/mild (scores F, 1 and 2), moderate (score 3) and severe (score 4); absent/mild (scores F, 1 and 2) and moderate/severe (scores 3 and 4 ).

All data were processed using the EPI-INFO software (CDC version 6.04b). Chi-square, chi-square for tendency and MannWhitney were employed to investigate the differences between groups according to the type of data. The criteria value to consider the variables for the multivariate analyses was $\mathrm{p}<0.10$. The binary logistical regression analysis using the stepwise method (forward selection) was performed with SPSS 13.0. The logistical model made it possible to estimate the occurrence of heterotopic ossification, based upon the risk factors included in the analysis. The evaluation of model adjustment and adequacy was obtained by the method of Hosmer-Lemeshow". Statistical significance for these analyses was established at $\mathrm{p}<0.05$.

Table 1. Categorical variables for the heterotopic ossification $(\mathrm{HO})$ and control groups with the odds ratios (OR), confidence intervals (95\% Cl) and significance levels ( $p$ values).

\begin{tabular}{|c|c|c|c|c|c|c|}
\hline \multirow[b]{2}{*}{ Variable } & \multirow[b]{2}{*}{ Category } & \multicolumn{2}{|c|}{$\mathrm{HO}$} & \multirow[b]{2}{*}{ OR } & \multirow[b]{2}{*}{$95 \% \mathrm{Cl}$} & \multirow[b]{2}{*}{$\mathrm{p}$ value } \\
\hline & & Yes & No & & & \\
\hline \multirow[t]{2}{*}{ Gender } & Female & 1 & 6 & 1.0 & - & - \\
\hline & Male & 32 & 27 & 7.1 & $0.8-166.8$ & 0.11 \\
\hline \multirow[t]{2}{*}{ Injury level } & Thoracic & 23 & 27 & 1.0 & - & - \\
\hline & Cervical & 10 & 6 & 2.0 & $0.5-7.3$ & 0.39 \\
\hline \multirow[t]{2}{*}{ Completeness of injury* } & Incomplete (B) & 9 & 12 & 1.0 & - & - \\
\hline & Complete (A) & 24 & 21 & 1.5 & $0.5-4.9$ & 0.60 \\
\hline \multirow[t]{3}{*}{ Spasticity } & Absent/mild & 14 & 25 & 1.0 & - & - \\
\hline & Moderate & 8 & 6 & 2.4 & $0.6-9.9$ & - \\
\hline & Severe & 11 & 2 & 9.8 & $1.7-75.3$ & $0.006^{* *}$ \\
\hline \multirow[t]{3}{*}{ Number of pressure ulcers } & 0 & 14 & 22 & 1.0 & - & - \\
\hline & 1 & 14 & 9 & 2.4 & $0.7-8.3$ & - \\
\hline & $>1$ & 5 & 2 & 3.9 & $0.6-34.5$ & $0.047^{* *}$ \\
\hline \multirow[t]{2}{*}{ Urinary complications } & 0 & 8 & 14 & 1.0 & & \\
\hline & $\geq 1$ & $25^{\#}$ & $19^{\dagger}$ & 2.3 & $0.7-7.6$ & 0.19 \\
\hline \multirow[t]{2}{*}{ Deep venous thrombosis } & No & 31 & 31 & 1.0 & $0.1-10.8$ & 0.61 \\
\hline & Yes & 2 & 2 & 1.0 & & \\
\hline \multirow[t]{2}{*}{ Smoking } & No & 22 & 26 & 1.0 & $0.5-6.5$ & 0.41 \\
\hline & Yes & 11 & 7 & 1.9 & & \\
\hline
\end{tabular}

*International standards for neurological and functional classification of spinal cord Injury ${ }^{9}$ ** Chi-square for tendency; ${ }^{*} 11$ had urinary lithiasis, none had vesicoureteral reflux, 4 had hydronephrosis, and 20 had infection of the urinary tract. Of the 33 patients, 5 were submitted to surgery of the urinary tract and two had other complications, such as chronic renal failure and pyelonephritis; ${ }^{\dagger}$ Infection was the most frequent complication (18 cases); 6 had lithiasis, 2 had vesicoureteral reflux, 4 had hydronephrosis, 3 were submitted to surgery of the urinary tract and 2 had other complications. 


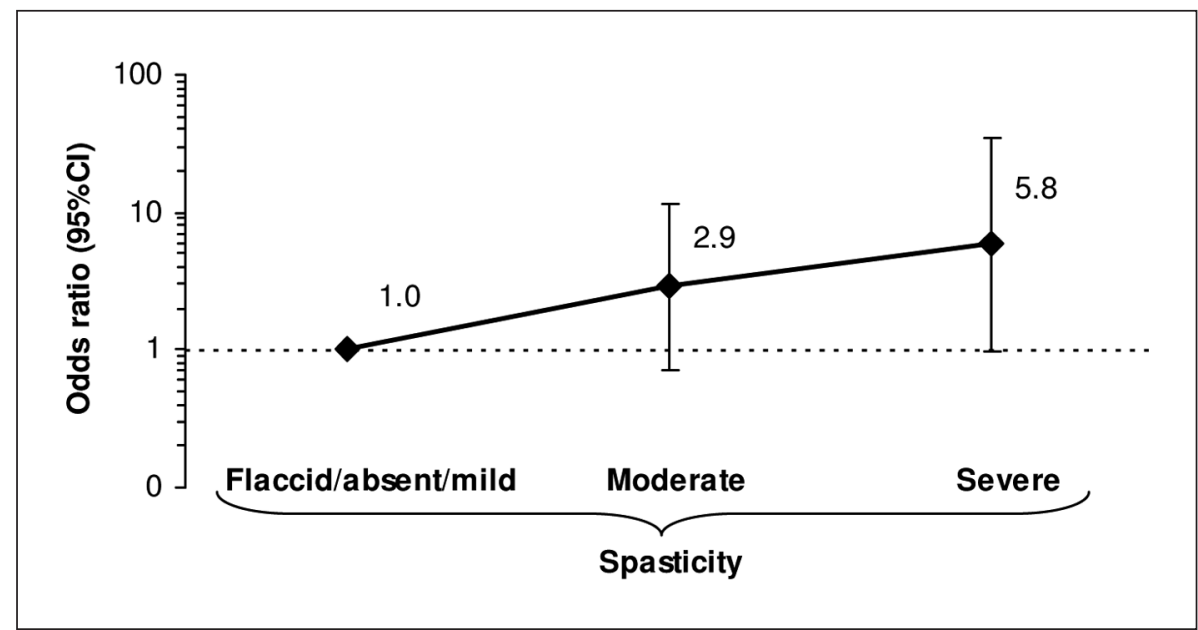

Figure. Odds ratio of spasticity and heterotopic ossification in patients with spinal cord injuries, adjusted to the number of pressure ulcers and time since injury. Although not significant, at initial model, there is a clear tendency of a positive relationship between spasticity and heterotopic ossification, which became evident when spasticity was dichotomized to flaccid/absent/mild and moderate/severe (final model, Table 2).

Table 2. Independent variables associated with the presence of heterotopic ossification in patients with traumatic spinal cord.

\begin{tabular}{lcccc}
\hline Variable & Coefficient** $^{*}$ & Odds Ratio & $\mathrm{Cl}(95 \%)$ & p value \\
\hline Spasticity* & 1.32 & 3.76 & $1.15-12.30$ & 0.029 \\
Number of pressure ulcers & 0.72 & 2.05 & $1.08-3.89$ & 0.028 \\
Time since injury (months) $^{\dagger}$ & 0.12 & 1.12 & $1.02-1.24$ & 0.023 \\
\hline
\end{tabular}

*Dichotomized to flaccid/absent/mild (Ashworth grades F, 1 and 2; as reference) and moderate/severe; ${ }^{* *}$ Constant coefficient $=-1.903 ;{ }^{\dagger}$ Odds ratio for 12 months $=e^{0.12 \times 12}=4.22$.

\section{RESULTS}

Among the 33 patients with heterotopic ossification, the hip joints were most affected with 21 cases, 14 of which were bilateral. The knees were also affected in six patients and, of those, just one was bilaterally. The severity of the heterotopic ossification was equally distributed with 11 patients for each classification levels (mild, moderate, and severe). In all cases and controls the automobile accidents prevailed ( $53 \%$ ), following by firearm lesions (26\%) and height fall (11\%). However, there was a larger proportion of lesions from firearm among cases in relation to controls ( $36 \%$ vs. $15 \% ; \chi^{2}=3.88, p=0.048$ ). There was no difference between the groups about associated lesions, with 14 cases and 18 controls ( $44 \%$ vs. $56 \% ; \chi^{2}=0.971$; $\mathrm{p}=0.325)$. Fractures and dislocations $(57 \%)$ predominate, equally distributed among the groups. In both groups predominated the fractures of the bones from the trunk in cases $(58 \%)$ and the controls (46\%). Previous physiotherapy was informed for more than two thirds of the individuals, without distinction between the groups ( 28 cases vs. 23 controls, $\chi^{2}=2.16 ; p=0.142$ ).
There were no differences between medians of cases and controls for age (30.0 vs. 27.0 years) and hospital length of stay (1.5 vs. 1.8 months). However, the median time since injury was 3 times larger in cases, compared to controls ( 8.6 vs. 2.8 months; $p=0.001$ ). The number of pressure ulcers was categorized according to its median, i.e., none, one, or more than one. Differences between the groups were found only for the variables related to the spasticity and number of pressure ulcers, both in the positive sense, in other words, as larger its magnitude, larger the association with the heterotopic ossification (Table 1).

After adjusting for the confounding variables, the number of pressure ulcers and the time since the injury continued to show associations with the presence of heterotopic ossification. The association of spasticity and heterotopic ossification followed a dose-response pattern, although no significant (Figure). Considering that the frequency of severe spasticity was low, with $20 \%$ of the total number of cases and controls, this variable was dichotomized: flaccid/absent/mild and moderate/severe. After 
these adjustments, the final logistical model was obtained (Table 2). Based on the adjusted odds ratio, it was possible to estimate that the presence of spasticity into three and four grades compared to those related to the absence or mild (F, 1, and 2 grades), lead to increases of $276 \%$ in the probability of being associated with heterotopic ossification. In addition, for each pressure ulcer, there was a probability of it being 105\% higher in the patients who developed heterotopic ossification. Finally, every year of lesion increases in $322 \%$ this association (Table 2).

\section{DISCUSSION}

The present study evaluated patients with traumatic spinal cord injuries with heterotopic ossification compared to controls. The bivariate analyses detected significant associations between the time of injury, number of pressure ulcers, degree of spasticity and firearm lesions with the development of heterotopic ossification. Based upon the final logistical model, the first three variables were independently associated, without interactions. Before considering these results, it is important to discuss methodological aspects involved in the investigation, as well as their implications.

The case-control design starts from the effects to identify the possible causes, configuring a typical retrospective study ${ }^{12,13}$. In this type of study, the relative risks are estimated by the odds ratio. The knowledge of the odds ratio permits the prediction of the occurrence of the heterotopic ossification, but this does not mean that its presence necessarily implied the development of heterotopic ossification. The odds ratios were only indirect measures of this probability, since there may also exist associations with other determinants with various conditions of interest ${ }^{12}$. The case-control design has various limitations, such as the bias of prevalence, which can only be avoided when the most recent cases are included ${ }^{12,13}$. The ideal situation would be to consider the initial stages of heterotopic ossification; however, this is a chronic condition and it is difficult to be identified early, unless employing a cohort design. To minimize this bias, it was decided not to include patients who had more than two years of spinal cord injury.

Another problem regarding case-control design is the selection of the control group and the lack of comparability between groups' characteristics. It is possible to restrict potential discrepancies by applying procedures, such as category limitations, matching, or making adjustments during the data analyses, like multivariate analy$\mathrm{sis}^{12}$. Retrospective data may not be appropriate due to the lack of information in the medical records or because they were only based upon the subjects' recall. Because of this, it is important that the assessments should be conducted by an independent investigator, who is blind to the group assignments ${ }^{12}$. In this study the heterotopic ossification cases were not blind to the investigator. However, this fact should not be considered to be relevant, since the variables were objective and easily identified in the patients' medical records. On the other hand, among the advantages of the case-control design, it is a fact that it is adequate for the investigation of rare conditions and a rapid, practical, and low-cost method to test the interaction effects of a great number of factors, which could potentially be related to the research in question ${ }^{12,13}$.

There were several difficulties to carry out the study protocol in the present research. First, the establishment of the heterotopic ossification diagnosis must be considered. The option to employ the imagery methods was due to their reported high sensitivity and specificity for diagnosing late heterotopic ossification ${ }^{14}$. This method does not supply the precocious diagnosis, because it becomes positive only two to four weeks after the beginning of the clinical signs, when there is mineral increase in the osteoid matrix. Our criterion had purpose of correctly discriminate the patients with and without heterotopic ossification. Because this criteria we were limited about the number of patients to compose the control group. Even so, considering a prevalence of the main risk factors for heterotopic ossification around $40 \%{ }^{5}$, an alpha of $5 \%$ and a minimum odds ratio of 4.0 , the calculated post hoc power of the study is of $76 \%$, which is considered acceptable.

In the literature, various studies were found related to heterotopic ossification in patients with spinal cord injuries, which focused on the clinical, diagnostic, and treatment aspects. However, considering causality, particularly using case-control design, only six were found, all using only bivariate analyses. Scher ${ }^{7}$ found association with complete lesions. Weiss et al..$^{15}$, and Hunter et al. ${ }^{16}$, studied patients with spinal cord and cerebral injuries and did not find any associations between heterotopic ossification and the histocompatibility antigens. However, Larson et al. ${ }^{17}$ demonstrated an increased frequency of HLA-B27 in patients with spinal cord injuries and heterotopic ossification. The findings of Lai et al. ${ }^{8}$ and Bravo-Payno et al. ${ }^{5}$ deserve some attention because of their methodological similarities with our study. They also made diagnoses of heterotopic ossification based upon radiographic findings. From 14 variables studied by Lai et al. ${ }^{8}$, age, complete injuries, pressure ulcers, and spasticity showed association with heterotopic ossification. Out of the nine variables investigated by Bravo-Payno et al. ${ }^{5}$, three were associated with the development of heterotopic ossification: complete injury, pressure ulcers, and spasticity. The findings of the present study were somewhat similar and only differed regarding the age and the extent of the injuries.

To complete these considerations, the variables iden- 
tified here should also be appraised according to causality criteria ${ }^{18}$ : strength, biological gradient (dose-response curve), consistency, analogy, plausibility (coherence) and temporality (temporal sequence). Thus, it should be pointed out that the associations between the risk factors and heterotopic ossification have been shown to be strong (odds ratio $>2$, Table 2). The study also evidenced that as larger the number of pressure sore, degree of spasticity and the time since injury, more susceptible was the patient to developing heterotopic ossification. Those results are consistent with previous studies ${ }^{5,8}$ and other non-progressive neurological conditions, as in the cerebral lesion, which also complicated with heterotopic ossification ${ }^{19,20}$. The three risk factors identified, as we will see ahead, are closely interrelated and, fundamentally, point to a cumulative effect of micro traumas. Finally, the chronological sequence among exposition to the risk factors and the outcome is a criterion little assisted in a case-control study ${ }^{12}$.

It is known that an inflammatory process due to localized pressure, spasticity, micro traumas and hemorrhages, may be responsible for the development of pressure ulcers and ossification ${ }^{5,21}$. In the same way, pressure ulcers could unchain spasticity and heterotopic ossification ${ }^{8}$. As we can observe, it is a triangle of interrelated conditions, where we do not have as to define precisely which is the trigger event. Among them, the time since injury also associates, demonstrating to be a slow process, progressive, cumulative and, possibly associated to a genetic susceptibility ${ }^{17,22}$. Our results provide further evidence that spasticity, pressure ulcers and time since injury are independent risk factors, with a confounder effect among them, without interaction. It is believed that after premature mobilization, the traumatized and scar connective muscular tissues become the site of fibroblastic proliferation. Local metabolic alterations would be related with neovascular formation and, probably, they would influence in the development of heterotopic ossification, as they act in the cellular differentiation ${ }^{23}$. Furthermore, vasomotor abnormalities, as arteriovenous fistulas and vascular hyperplasia of the surround tissues, can be also relevant in this processes ${ }^{23}$.

Thus, isolated or in combination, several theories have been proposed to determine the etiology of heterotopic ossification, which considered the mechanisms such as inductors of osteal matrices ${ }^{24}$, chemical factors ${ }^{25}$, tissue hypersensitivity, auto-immune responses, and genetic factors ${ }^{16,22,24,26}$. Until now, no scientific support has been suggested for these hypotheses ${ }^{16,27,28}$. More recently, another interesting suggestion was added, including the contributions of a proprioception dysfunctions ${ }^{29}$. In summary, it appears that central and local mechanisms are involved in the process of heterotopic ossification. The central mechanisms may be genetic, hormonal, or metabol- ic, whereas the local mechanisms may also include microtraumas, immobilization, infections, pressure ulcers, and vasomotor disturbances.

Heterotopic ossification is a clinical complication of great impact since, depending on its extent, it may lead to various degrees of limitations in the range of motion and even anchylosis. In its more advanced stages, it can become an extremely disabling condition, limiting the objectives of the rehabilitation. Often, the patient is unable to neither assume the orthostatic and sitting positions nor adopt adequate postures due to anchylosis of one or more joints. While the exact mechanisms involved in its genesis are still unknown, it is important to identify the risk factors to be able to prevent and even detect this condition. In conclusion, it seems that spasticity, pressure ulcer, and time since injury are risk factors of heterotopic ossification in adult spinal cord injury patients with less than two years of injury. These results confirm previous abroad studies and call attention to the potential of prevention of this serious complication.

\section{REFERENCES}

1. Hernandez AM, Forner JV, de la Fuente T, Gonzalez C, Miro $\mathrm{R}$. The para-articular ossifications in our paraplegics and tetraplegics: a survey of 704 patients. Paraplegia 1978;16:272-275.

2. Blane CE, Perkash I. True heterotopic bone in the paralyzed patient. Skeletal Radiol 1981;7:21-25.

3. Freehafer AA, Yurick R, Mast W. Para-articular ossification in spinal cord injury. Med Services J 1966;22:471-478.

4. Wharton GW, Morgan TH. Ankylosis in the paralyzed patient. J Bone Joint Surg [Am] 1970;52:105-112.

5. Bravo-Payno P, Esclarin A, Arzoz T, Arroyo O, Labarta C. Incidence and risk factors in the appearance of heterotopic ossification in spinal cord injury. Paraplegia 1992;30:740-745.

6. Wittenberg RH, Peschke U, Botel U. Heterotopic ossification after spinal cord injury. Epidemiology and risk factors. J Bone Joint Surg [Br] 1992;74:215-218.

7. Scher AT. The incidence of ectopic bone formation in post-traumatic paraplegic patients of different racial groups. Paraplegia 1976;14:202-206.

8. Lal S, Hamilton BB, Heinemann A, Betts HB. Risk factors for heterotopic ossification in spinal cord injury. Arch Phys Med Rehabil 1989;70:387-390.

9. Maynard FMJ, Bracken MB, Creasey G et al. International Standards for Neurological and Functional Classification of Spinal Cord Injury. American Spinal Injury Association. Spinal Cord 1997;35:266-274.

10. Ashworth B. Preliminary trial of carisoprodol in multiple sclerosis. Practioner 1964;192:540-542.

11. Lemeshow S, Hosmer DW Jr. A review of goodness of fit statistics for use in the development of logistic regression models. Am J Epidemiol 1982;115:92-106.

12. Austin H, Hill HA, Flanders WD, Greenberg RS. Limitations 
in the application of case-control methodology. Epidemiologic Review 1994;16:65-76.

13. Pereira MG. Métodos empregados em epidemiologia. In Pereira MG (Ed). Epidemiologia: teoria e prática. Rio de Janeiro: Guanabara Koogan, 1995:269-288.

14. Oliveira GS, Ares M. Calcificação heterotópica em lesão medular. Acta Fisiátrica 1998;5:128-134.

15. Weiss S, Grosswasser Z, Ohri A, et al. Histocompatibility (HLA) antigens in heterotopic ossification associated with neurological injury. J Rheumatol 1979;6:88-91.

16. Hunter T, Dubo HI, Hildahl CR, Smith NJ, Schroeder ML. Histocompatibility antigens in patients with spinal cord injury or cerebral damage complicated by heterotopic ossification. Rheumatol Rehabil 1980;19:97-99.

17. Larson JM, Michalski JP, Collacott EA, et al. Increased prevalence of HLA-B27 in patients with ectopic ossification following traumatic spinal cord injury. Rheumatol Rehabil 1981; 20:193-197.

18. Hill AB. The environment and disease: association or causation? Proc R Soc Med 1965;58:295-300.

19. Garland DE, Hanscom DA, Keenan MA, Smith C, Moore T. Resection of heterotopic ossification in the adult with head trauma. J Bone Joint Surg [Am] 1985;67:1261-1269.

20. Garland DE. Clinical observations on fractures and heterotopic ossification in the spinal cord and traumatic brain injured populations. Clin Orthop 1988;687:86-101.
21. Vanden BL, Vanderstraeten G. Heterotopic ossification: a review. J Rehabil Med 2005;37:129-136.

22. Ritter MA, Biegel AA, Bray RA, Bintz M. HLA antigens and ectopic ossification following total hip arthroplasty. Contemp Orth 1984;8:45-48.

23. Chantraine A, Heynen G, Franchimont P. Bone metabolism, parathyroid hormone, and calcitonin in paraplegia. Calcif Tissue Int 1979;27:199-204.

24. Urist MR, Strates BS. Bone formation in implants of partially and wholly demineralized bone matrix: including observations on acetone-fixed intra and extracellular proteins. Clin Orthop 1970;71:271-278.

25. Bridges JB, Pritchard JJ. Bone and cartilage induction in rabbit. J Anat 1958;92:28-38.

26. Minaire P, Betuel H, Girard R, Pilonchery G. Neurologic injuries, paraosteoarthropathies, and human leukocyte antigens. Arch Phys Med Rehabil 1980;61:214-215.

27. Garland DE, Alday B, Venos KG. Heterotopic ossification and HLA antigens. Arch Phys Med Rehabil 1984;65:531-532.

28. Ohry A. Paraosteoarthropaties and HLA. Arch Phys Med Rehabil 1980;61:427.

29. Paz AC, Carod Artal FJ, Kalil RK. The function of proprioceptors in bone organization: a possible explanation for neurogenic heterotopic ossification in patients with neurological damage. Med Hypotheses 2007;68:67-73. 